\title{
AMÉRICA LATINA Y EL CARIBE EN ZONA DE RIESGO: LA PANDEMIA DE COVID-19 Y LA DOCTRINA DEL SHOCK
}

\author{
AMÉRICA LATINA E CARIBE NA ZONA DE RISCO: A PANDEMIA DE \\ COVID-19 E A DOUTRINA DO CHOQUE
}

LATIN AMERICA AND THE CARIBBEAN IN THE RISK ZONE: THE COVID-19 PANDEMIC AND THE DOCTRINE OF SHOCK

DOI: 10.22481/rbba.v10i02.9746

\begin{abstract}
María Carolina Caputto
Universidad Nacional del Litoral, Santa Fe, Argentina ORCID: https://orcid.org/0000-0001-7703-1970

Endereço eletrônico: carocaputto@ hotmail.com
\end{abstract}

\begin{abstract}
RESUMEN
El presente artículo se postula como una advertencia respecto al eventual uso de la situación de crisis provocada -o, mejor dicho, agudizada- por la pandemia de COVID-19 en los países de Latinoamérica y el Caribe, a través de un análisis sustentado en la "doctrina del shock" postulada por la escritoria, periodista y activista canadiense Naomi Klein. Luego de un repaso histórico donde se pueden encontrar sus argumentos, el trabajo analiza por qué motivos interpreto que el derecho humano a la salud de los ciudadanos de nuestra región se encuentra bajo amenaza, en el contexto de la actual pandemia. Para concluir, sostengo y busco justificar que la Bioética de vertiente latinoamericana puede resultar eficaz para abordarla críticamente y con sólidos argumentos humanistas y racionales, alzando la voz en los distintos ámbitos contra toda pretensión de subestimar la calidad de derecho humano del derecho a la salud y, con ello, el rol del Estado como garante de la dignidad de la persona y los derechos fundamentales.
\end{abstract}


Palabras clave: Pandemia. Derecho a la salud. Cobertura universal de salud. Bioética.

\title{
RESUMO
}

Este artigo é postulado como um alerta para o eventual aproveitamento da situação de crise provocada - ou, melhor, exacerbada - pela pandemia COVID-19 nos países da América Latina e Caribe, por meio de uma análise baseada na "Doutrina de Choque" postulado pela escritora, jornalista e ativista canadense Naomi Klein. Após uma revisão histórica onde se encontram seus argumentos, o trabalho analisa por quais motivos eu interpreto que o direito humano à saúde dos cidadãos de nossa região está ameaçado, no contexto da atual pandemia. Para concluir, defendo e procuro justificar que a Bioética de cunho latinoamericano pode ser eficaz para abordá-la criticamente e com sólidos argumentos humanísticos e racionais, levantando voz nos diversos campos contra qualquer pretensão de subestimar a qualidade do direito humano de o direito à saúde e, com isso, o papel do Estado como fiador da dignidade da pessoa e dos direitos fundamentais.

Palavras-chave: Pandemia. Direito à saúde. Cobertura universal de saúde. Bioética.

\begin{abstract}
This article is postulated as a warning regarding the eventual use of the crisis situation caused -or, rather, exacerbated- by the COVID-19 pandemic in the countries of Latin America and the Caribbean, through an analysis based on the "Shock Doctrine" postulated by Canadian writer, journalist and activist Naomi Klein. After a historical review where her arguments can be found, the work analyzes for what reasons I interpret that the human right to health of the citizens of our region is under threat, in the context of the current pandemic. To conclude, I maintain and seek to justify that Latin American Bioethics can be effective to approach it critically and with solid humanistic and rational arguments, raising the voice in the different fields against any pretense of underestimating the quality of the human right of the right to health and, with this, the role of the State as guarantor of the dignity of the person and fundamental rights.
\end{abstract}

Keywords: Pandemic. Universal healthcare coverage. Bioethics. 
COVID-19 Y LA DOCTRINA DEL SHOCK

\section{INTRODUCCIÓN}

Sin dudas la pandemia de COVID-19 será señalada como un fenómeno sanitario que marcó un antes y un después en la historia de la humanidad, generando repercusiones de toda índole y crisis de todo tipo (sanitaria, social, ambiental y económica) en un planeta ya en crisis, en particular en los países más castigados en el esquema socioeconómico planetario. Asimismo, la pandemia desnudó nuevas vulnerabilidades, por ejemplo, la del personal de salud expuesto a contagiarse, más aún ante la falta de elementos personales de protección como desencadenante ${ }^{\text {ii }}$.

El sistema económico capitalista en el que nos encontramos inmersos ciertamente no ayuda en la crisis: como lo advertía Marcuse tiempo atrás, el aparato capitalista determina la existencia diaria de las personas, sus necesidades y sus aspiraciones, y perpetúa la servidumbre, la miserable lucha por la existencia ante los mismos ojos de las nuevas posibilidades de libertad activa e intensifica en esta sociedad una agresividad primaria hasta un grado, creo, desconocido hasta ahora en la historia ${ }^{\mathrm{iii}}$. ¿Cuáles serían las sensaciones de Marcuse en la realidad actual en la que, lamentablemente advertimos que la agresividad no sólo no ha ido en descenso, sino que se ha exacerbado?

Apunto por considerar relevante un dato crucial para entender la incidencia de la economía de mercado en materia de salud, considerado un asunto privado $-\mathrm{O}$, a lo sumo, público, de higiene y salubridad- previo al descubrimiento de los medicamentos en gran escala, puntualmente, los antibióticos y vacunas. Distintos autores que han estudiado la denominada "medicalización de la vida" refieren que en la segunda mitad del siglo XX, la caída del Acuerdo de Bretton Woods, el neoliberalismo y la posmodernidad, posibilitaron la transformación de la medicina en un objeto de mercado que, con el modelo educativo del Informe Flexner de la Fundación Rockefeller, constituyó el caldo de cultivo ideal del proceso y de la medicalización indefinida con el mezquino fin de maximizar el lucro obsceno obtenido de la medicina como mercancía ${ }^{\text {iv }}$.

De hecho, y merced al andamiaje de un capitalismo desmedido, hoy la lucha por el dominio del mercado de las vacunas para hacer frente a la pandemia de COVID-19 no parece tener por fin la salud pública a nivel global, sino ganar la disputa existente entre los distintos laboratorios, para incrementar sus ya delirantes ganancias. De otra manera, no se explicaría el férreo rechazo a la liberalización de las patentes ${ }^{v}$ o que recién a fines de julio de 2021, Haití era el único país de América sin una sola dosis de la vacuna COVID-19 ${ }^{\text {vi }}$.

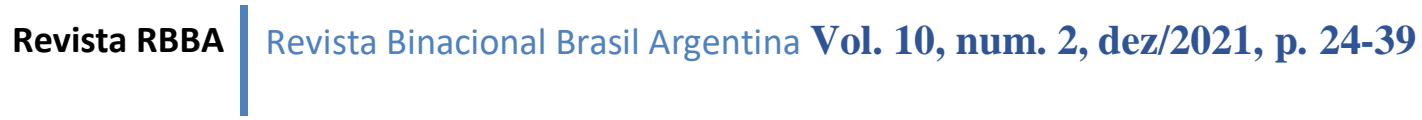


Pues bien, más allá de tales referencias, en este breve trabajo me excuso por no hacer tanto foco en la problemática de la pandemia de COVID-19 en nuestra región, sino en una mirada más prospectiva desde las ideas que la escritoria y periodista canadiense Naomi Klein describe en su libro "La doctrina shock: el auge del capitalismo del desastre", con especial hincapié la actual amenaza al derecho a la salud en nuestra región, y tentando a la bioética como instrumento efectivo para la reflexión.

\section{EL SHOCK COMO CATALIZADOR DEL SISTEMA CAPITALISTA GLOBAL}

Básicamente, en la obra citada, la autora plasma sus impresiones sobre el uso que se ha hecho de situaciones de desesperanza para instalar el libre mercado en un capitalismo puro, bajo la consigna de que las fuerzas económicas de la oferta, demanda, inflación y desempleo son como las fuerzas de la naturaleza, fijas e inmutables, de modo que -al igual que se autorregulan los ecosistemas, manteniéndose en equilibrio-, el mercado, si se le deja a su libre albedrío, alcanza el equilibrio por sí solo.

Las bases de tal doctrina, nacida en la década de 1970 y cuyo referente máximo fue el economista norteamericano Milton Friedman -uno de los creadores de la denominada "Escuela de Chicago"-, a quien la autora menciona como el "gran gurú" del capitalismo de libre mercado y responsable de crear la hoja de ruta de la economía global. Sea o no que el mismo haya tenido tal trascendencia, lo interesante de la obra de Klein, y que referencia con datos históricos e innumerables citas, se relaciona con la metodología de instalación del sistema económico contemporáneo: la doctrina nacida en Chicago postula que una crisis o un estado de shock colectivo (provocado por una guerra, un catástrofe natural, una emergencia sanitaria, etc.) brinda las posibilidades de llevar adelante cambios político-económicos radicales, al tiempo que se suspenden temporal o permanentemente las reglas del juego democrático. Se sostiene un compromiso con una trinidad política: la eliminación del rol público del Estado a través de las privatizaciones, una desregulación que de absoluta libertad de movimientos de las empresas devenidas en verdaderas corporaciones- y un recorte del gasto social que lo torna prácticamente nulo $^{\text {vii }}$. Así, a partir del shock provocado por un hecho catastrófico, aprovechando el miedo y la incertidumbre de la población, se adoptan medidas a la velocidad de la luz que mudan el sistema político-económico público hacia uno en manos privadas, sin mayor regulación ni control del Estado que, así, va quedando al margen de sus compromisos constitucionales.

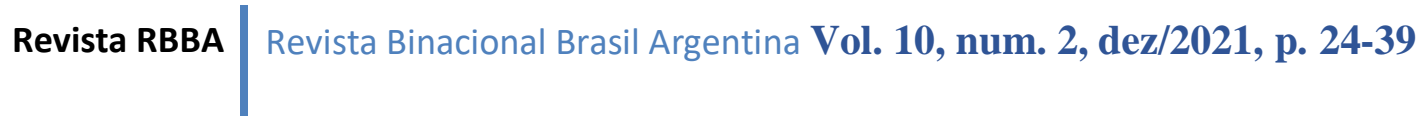


La doctrina del shock expuesta por Klein, veremos que tuvo hondas repercusiones en América Latina. Haciendo un poco de historia, y si bien desde la época de la conquista y el genocidio de nuestros pueblos originarios la región fue objeto de inmisiones y abusos por parte de potencias extranjeras, en las primeras décadas del siglo pasado se vivió un tiempo de cierto desarrollismo mientras Europa central estaba ocupada con las guerras mundiales. Sin embargo, el encantamiento no duró mucho: en la mayoría de los países del cono sur se fueron dando sucesivos golpes de Estado que derrocaron a gobiernos democráticos, instalando dictaduras militares o cívico-militares que fueron abonando el terreno para el aterrizaje del neoliberalismo a través del desprendimiento de los países de sus recursos públicos a manos privadas.

Klein sostiene que el primer "experimento" que supuso la aplicación de la doctrina del shock fue Chile, en oportunidad de la caída del gobierno democrático del presidente socialista Salvador Allende en 1973 por el General Augusto Pinochet. La estrategia fue multinivel: desde el punto de vista político-militar, los años previos al golpe asesores estadounidenses hicieron un prolijo trabajo instalando ideas anticomunistas a las fuerzas armadas; desde la faceta económica, distintas alianzas promovieron la formación de estudiantes latinoamericanos en la licenciatura de economía de la Escuela de Chicago -en parte por una donación de la Fundación Ford- para la instalación definitiva de ideas libremercadistas y anti desarrollistas; también existió una faceta con algunos líderes empresariales chilenos opositores al gobierno de Allende.

El proyecto Chile luego se expandió a Brasil, Uruguay, Argentina, Bolivia, sólo en nuestra región, pero también se extendió a Polonia, Corea del Sur, Sudáfrica, Rusia, Tailandia, Filipinas, Irak, etc. en una franca arremetida de indiscutido tinte colonialista, al igual que los acontecimientos bien caracterizados por Robert Cox que se sucedieron a partir de llamada “Guerra al Terror", luego del atentado al World Trade Center en nombre de una supuesta seguridad global ${ }^{\text {viii }}$.

Pasados los hechos que dieron pie a la fijación de tal sistema político, económico y social fuera de los EE.UU., a finales de los '80, el mismo se perfeccionó mediante el conocido “Consenso de Washington” y la instalación en terreno latinoamericano de las diez premisas elaboradas por organismos financieros internacionales, como el Fondo Monetario Internacional, que definieron a una nueva modalidad de capitalismo como sistema político económico de libre mercado sin límites, al que el economista Williamson bautizó como neoliberalismo ${ }^{\mathrm{ix}}$.

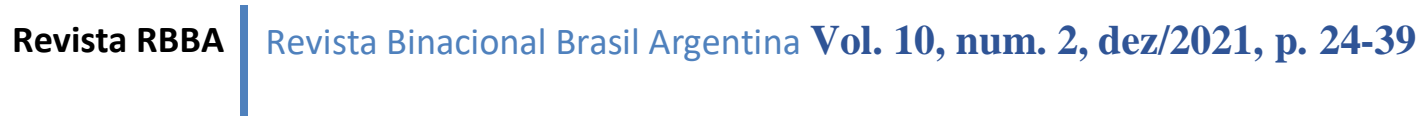


Luego, en los últimos años, se fue instalando el "Consenso de los Commodities" que, en palabras de Svampa, es "sostenido por el boom de los precios internacionales de las materias primas y los bienes de consumo cada vez más demandados por los países centrales y las potencias emergentes" y que provoca nuevas asimetrías y conflictos sociales, conómicos, ambientales y político culturales $(2013$, p. 31) . La perpetuación y agudización de dicho régimen de explotación mostró nuevas fronteras mediante la globalización, con el cual se advierte un intercambio a gran escala de bienes y servicios, facilitado por el auge de la tecnología en la comunicación, y el repliegue aún mayor del rol del Estado para dejar vía libre al mercado, con una fuerte concentración de la riqueza en pocas manos. Esta "mano invisible del mercado", citando a Baumann, permite a los ricos "moverse libremente, buscar y encontrar los mejores terrenos para obtener los mayores beneficios, lo que les hará más ricos”, pero también incide en los mercados de trabajo, haciendo que los pobres se vean condenados a empobrecerse aún más $(2014, \text { p. 51) })^{\mathrm{xi}}$, siendo la lógica de la ganancia la que está dominando la racionalidad de intercambio y distribución ${ }^{x i i}$. Así lo demuestran los periódicos informes de OXFAM: en uno de ellos, publicado en el 2017, el $1 \%$ más rico de la población mundial posee más riqueza que el resto del planeta ${ }^{x i i i}$.

\section{EL IMPACTO DEL MODEO NEOLIBERAL SOBRE EL DERECHO A LA SALUD}

En el modelo descripto, pues, el Estado queda reducida a su mínima expresión, considerando a la libertad personal como el valor supremo. Según Mainetti, se está ante una nueva fase del individualismo occidental, caracterizada por el desinterés por lo social y lo político, y en la que sólo cuenta el individuo y su autosuficiencia existencial ${ }^{\mathrm{xiv}}$. No es de extrañarse que tal posición considere moralmente cuestionables las medidas del Estado para redistribuir la riqueza o garantizar el derecho a la protección de la salud: pero sí está obligado a proteger la propiedad privada de quien invierte en salud ${ }^{\mathrm{xv}}$.

En efecto, como puede lógicamente deducirse, las ideas en que se fundó influyeron definitivamente en la consideración sobre quién se hace cargo de brindar servicios de salud, agregándose a partir de los años '70 al "complejo médico industrial" el "complejo médico financiero" por cuanto la salud entró a partir de entonces en la lógica financiera del seguro ${ }^{\mathrm{xvi}}$.

Así, no sorprende que quienes tienen intereses en el mantenimiento del sistema capitalista global busquen acentuar su carácter mercantilista -por ellos mismos instalado- , desdibujando la naturaleza del derecho humano fundamental a la salud y corrompiendo los

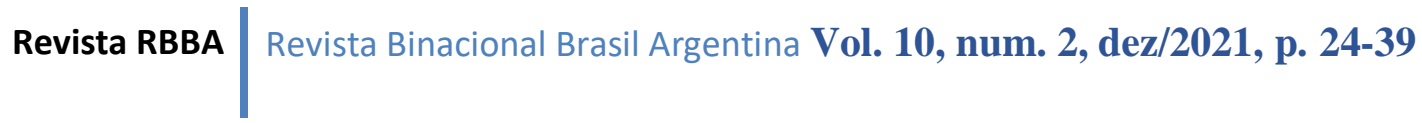


nobles objetivos de organizaciones internacionales, incidendo definitivamente en su descrédito cada vez mayor. Así, la Declaración de Alma-Ata (1978) de la OMS es muestra elocuente de ese reduccionismo ${ }^{\text {xvii }}$ o, más recientemente, el documento "Invertir en Salud" de 2003 en donde el vocablo "derecho" se menciona en seis oportunidades vinculadas a la protección de los derechos de propiedad intelectual, las patentes y las licencias, pero ni una sola vez aparece mencionado el "derecho a la salud"xviii.

El modelo neoliberal compromete el carácter de derecho humano de la salud por cuanto las responsabilidades asumidas al respecto por los Estados (por ejemplo, muy elocuentemente en el PIDESC) buscan ser diluídas. Las determinaciones de salud no dependen ya sólo de decisiones individuales, o de gobiernos particulares, sino de complejas relaciones políticas, económicas, sociales y culturales, mantenidas por lo que Cox menciona como un aglomerado difuso, etéreo, volátil, pero denso y cohesionado, de instituciones, grupos, reuniones y eventos ocultos o declarados que actúan en la conformación de la agenda hegemónica global, para la que dicho autor utiliza la metáfora de la "nebulosa"xix. Es allí donde cobran creciente importancia las agencias y organizaciones gubernamentales e intergubernamentales, así como los medios, las fundaciones privadas con gran influencia internacional y corporaciones transnacionales $^{\mathrm{xx}}$. Tales, la Fundación Rockefeller -a la cual se acusa de haber carterizado a la medicina a partir del Informe Flexner-, la Fundación Ford, la Fundación Gates, el Banco Mundial, el FMI, entre otros.

Bien o malintencionadamente, el fenómeno descripto provoca la distinción entre los conceptos de "salud internacional" y el novedoso de "salud global", presuponiendo este último una "mirada" planetaria sobre cuestiones que involucran la salud de toda la humanidad ${ }^{\mathrm{xxi}}$, y no la relativa a asuntos, acuerdos y políticas sanitarias entre distintas naciones.

El concepto de salud global requiere cambiar el enfoque clínico tradicional por un enfoque integral e interdisciplinar de salud preventiva que atienda a los determinantes sociales y ambientales de la salud, que se enfrente a las desigualdades en salud inter e intranacional, y que se vea como un problema de interdependencia entre países desarrollados y en desarrollo ${ }^{\mathrm{xxii}}$.

\section{IV. ¿POR QUÉ MOTIVO LA PANDEMIA DE COVID-19 ES UNA AMENAZA PARA LA SALUD DE LOS HABITANTES DE NUESTRA REGIÓN?}

América Latina se presenta desde el 2020 como tierra fértil para una nueva embestida de la doctrina del shock pues la pandemia de COVID-19 la afecta puntual y gravemente gxiii $^{\text {. }}$

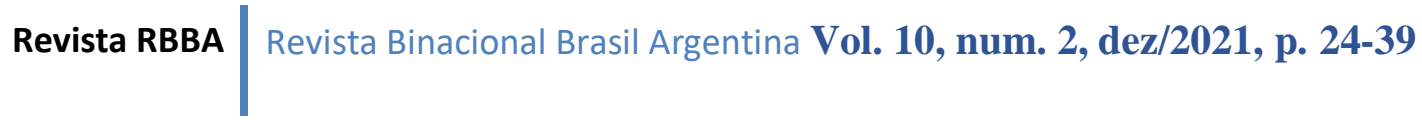


Nuestra región se encuentra en deuda con la población en lo que atañe a los condicionantes sociales de la salud: la brecha entre los más richos y los más pobres, los altos índices de pobreza e indigencia, la malnutrición, la enorme deuda pública, la degradación ambiental, el analfabetismo, etc. La pandemia deja al desnudo un sinnúmero de situaciones de injusticia y arrastre de problemas sistémicos reproducidos desde hace décadas.

Y, en esto no digo nada novedoso, nuestros gobiernos -salvo los de sostenidas raíces socialistas o de izquierda- se han visto históricamente tentados por el liberalismo, permitiendo el saqueo a las riquezas estatales, la huida de capitales sin control y la desregulación de sus economías, ante la parsimonia de la mayoría del pueblo, incapaz de advertir las consecuencias de ello en su calidad de vida.

Elocuente muestra de ello es el último informe del Programa de las Naciones Unidas para el Desarrollo que, considerando que la región se caracteriza por la concentración de poder en manos de unos pocos que defienden sus intereses privados, explora el rol de las elites económicas en el bloqueo a reformas de los sistemas impositivos en pro de una redistribución de la riqueza $(2021)^{\mathrm{xxiv}}$. De hecho, y tal como lo denuncia el Centro de Estudios para América Latina (CEPAL), en general, en Argentina y Latinoamérica, la presión tributaria sobre los sectores de mayores ingresos es baja en comparación con los países más ricos, entendiendo que es "justo y necesario" pedir a quienes concentran la riqueza "una contribución extraordinaria en el contexto de una emergencia social, económica y sanitaria"xxv .

Teniendo en cuenta lo dicho, el presente trabajo se centra en el serio y grave riesgo que la región corre actualmente, relacionado con el posible uso de la doctrina del shock -provocado éste por la pandemia de COVID-19- como catalizadora para la definitiva implementación de la Cobertura Universal de Salud (CUS), estrategia sanitaria impulsada por organismos internacionales (OMS - OPS) desde, por lo menos, 2005, pero que se transforma en el eje central de la estrategia de reformas para la región a partir del $53^{\circ}$ Consejo Directivo y $66^{\circ}$ Sesión del Comité Regional de la OMS para las Américas en Octubre de 2014, con resultados poco auspiciosos en los países en que fue impuesto, como México, Colombia y Chile ${ }^{x x v i}$.

La CUS, impulsada por el "complejo médico financiero", lejos de los nobles objetivos que exterioriza, no protege el derecho a la salud en los términos en que se han comprometido internacionalmente los Estados mediante acciones positivas, a través de garantizar el acceso universal, igualitario y adaptado a las necesidades de salud de cada uno de los ciudadanos. Todo lo contrario: CUS representa un paquete limitado de servicios disponible para las personas y

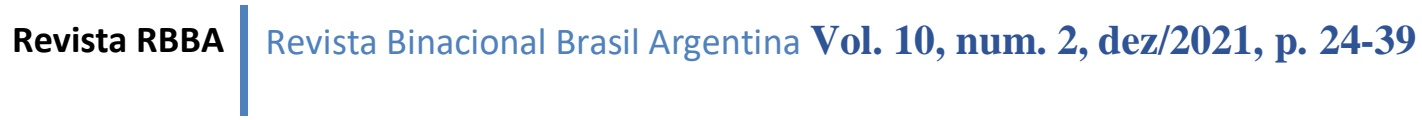


grupos "cubiertos" por pólizas, preferencialmente más pobres o en situación de "riesgo financiero", que invierte las prioridades de las políticas sanitarias al tener por objetivo garantizar la salud de los sistemas económicos y financieros en detrimento de la salud de los seres humanos ${ }^{\mathrm{xxvii}}$.

La adopción de tal modelo de cobertura, basado en la lógica del seguro y principios de mercado, supone -entre otros rasgos- el desmonte del sistema estatal, la asignación de la administración al sector privado, la segmentación en la prestación de servicios, un Estado débil o inexistente como ente rector de la salud y el fortalecimiento de grupos privados encargados de administrar los recursos ${ }^{\mathrm{xxviii}}$, con la única mira en el incremento de sus ganancias.

En el caso del Brasil, su Consejo Nacional de Salud actualmente está pugnando por la importancia del Sistema Único de Salud (SUS) ${ }^{\text {xxix }}$, comprometido en su ejecución tras la 95ma. Enmienda constitucional de 2016 que congeló el presupuesto de salud por veinte años ${ }^{\mathrm{xxx}}$.

En el caso de Argentina, durante el gobierno del ex presidente Macri existió una fuerte presión para la instalación de la CUS, visibilizada elocuentemente mediante la disolución del Ministerio de Salud y su transformación en Secretaría bajo la órbita del Ministerio de Desarrollo Social, lo cual implica muestra de la pérdida de razón de ser de la cartera sanitaria y una forma de desligarse de "la responsabilidad de actuar sobre los determinantes sociales de la salud sobre los cuales se debe hacer promoción y prevención, funciones que pasan a otras órbitas ministeriales" $(2020)^{\mathrm{xxxi}}$. Las características particulares de la CUS en Argentina se plasmaron en el Decreto de Necesidad y Urgencia $\mathrm{N}^{\circ} 908 / 16$, pero su final implementación efectiva a través del acuerdo con las distintas provincias fue disímil. No obstante, en junio del corriente año el Decreto $N^{\circ}$ 404/21 parece haber zanjado la cuestión, al haberse aprobado el Modelo de Convenio con el Banco Internacional de Reconstrucción y Fomento destinado a financiar parcialmente el Proyecto de Cobertura Universal de Salud Efectiva en Argentina. Toda una sorpresa.

\section{LA BIOÉTICA LATINOAMERICANA EN EL ACTUAL ESCENARIO}

Teniendo en consideración el panorama descripto, quienes nos interesamos en el campo de la bioética no podemos asumir una conducta indiferente frente a las patentes condiciones de injusticia e inequidad en salud que aquél provoca, agravadas hoy en el contexto de la pandemia por COVID-19, sobre todo en nuestras latitudes. Tomamos un compromiso y nos hacemos carne de una responsabilidad ética de provocar la reflexión a su respecto.

Revista RBBA $\mid$ Revista Binacional Brasil Argentina Vol. 10, num. 2, dez/2021, p. 24-39 
Décadas atrás, y aún previamente a que el neoliberalismo de su estocada final en el marco de la globalización, ya decía Marcuse que "el cambio social radical es objetivamente necesario por ser la única chance de salvar las posibilidades de libertad humana" ${ }^{\text {xxii }}$. El interrogante no tarde en llegar: ¿es asequible un cambio de esa naturaleza?

Si algo merece destacarse es que América Latina da muestras históricas de haber alzado la voz firmemente contra fuertes atropellos a los derechos de su pueblo a través de distintas corrientes y movimientos: la idea liberación en el ámbito de las ciencias sociales y pedagogía (Paulo Freire), en filosofía (Arturo Roig, Franz Hinkelammert, Enrique Dussel); en teología (Segundo Galilea, Hugo Assman), el pensamiento alternativo; los representantes de la filosofía latinoamericana (Gaos, Romero) y, muy particularmente, la Bioética Latinoamericana y sus distintas formulaciones (de Protección -Schramm, Kottow-, de Intervención -Garrafa-, centrada en los Derechos Humanos Universales -Tealdi-, etc.), decisivas en relación a su influencia en la redacción del texto final de la Declaración Universal de Bioética y Derechos Humanos de la UNESCO ${ }^{\text {xxxiii }}$.

En efecto, la preocupación por la inequidad en salud y las precarias condiciones de vida de una gran porción del pueblo latinoamericano motivó que que en la elaboración del texto definitivo de la Declaración Universal de Bioética y Derechos Humanos de la UNESCO, de 2005, las representaciones de América Latina tuviesen una participación activa. Los bioeticistas latinoamericanos llamaron la atención sobre un tipo de vulnerabilidad generado por procesos sociales, económicos, culturales, etc.: la vulnerabilidad social. Pugnaron allí para incorporar esa idea a través de la formulación de principios a incorporar en el instrumento, de modo de responder la realidad social de los países no desarrollados, no sólo de la región. Se plasmó dicho esfuerzo en la Carta de Buenos Aires de $2004^{\text {xxxiv }}$, en las reuniones convocadas por el Comité Intergubernamental de Bioética de la UNESCO, con el liderazgo de Brasil, consiguiendo así pautar su agenda antihegemónica ${ }^{\mathrm{xxxv}}$.

Obra emblemática de lo manifestado viene a ser el Diccionario Latinoamericano de Bioética, dirigido por el doctor Juan Carlos Tealdi, pero en cuya construcción participaron autores de distintos países de Latinoamérica y el Caribe como los referenciados supra, y otros de honda formación y compromiso social ${ }^{\mathrm{xxxvi}}$. Muchos de ellos integran a su vez la Red Latinoamericana y del Caribe de Bioética, y son autores de criteriosos artículos y podcasts que se publican en una revista que hoy resulta de ineludible lectura: la de la Red Bioética/UNESCO ${ }^{\mathrm{xxxvii}}$.

Revista RBBA $\mid$ Revista Binacional Brasil Argentina Vol. 10, num. 2, dez/2021, p. 24-39 
Así, hoy por hoy, somos varios los autores que entendemos que gran parte de los problemas existentes en las sociedades actuales, fruto de las producción y reproducción social capitalista neoliberalista, pueden ser confrontados a través de críticas bien fundamentadas, proponiendo para ello a la bioética ${ }^{\mathrm{xx} x \mathrm{iii}}$, mas advirtiendo que la Bioética clásica se muestra insuficiente para la salud pública ${ }^{\mathrm{xxxix}} \mathrm{e}$, incluso, que reproduce el patrón colonial ${ }^{\mathrm{x} 1}$.

Heinzmann y Fonti, en este sentido, postulan:

Enfrentamos una serie de conflictos donde la bioética puede aportar su actividad, en tanto puede ser el "lugar" donde se reúnen argumentos, se evalúan intereses, se identifican cursos de acción y consecuencias previsibles, y finalmente se da lugar a procedimientos capaces de identificar las opciones que beneficien al bien común, particularmente teniendo en cuenta a quienes habitualmente no llegan a las mesas de negociación (HEINZMANN y FONTI, 2014, p. 66).

En particular, entonces, el efecto transformador es propuesto a través de un modelo de Bioética pluralista, abierto, democrático, pero fundamentalmente crítico, que promueva un análisis profundo y una mayor problematización, colabore en superar el contexto de desigualdad e injusticia en materia de salud que caracteriza a nuestra región, y dé un enfoque que priorice en serio la dignidad y los derechos humanos de todos y todas.

\section{A MODO DE CONCLUSIÓN}

Los antecedentes históricos reseñados dan cabal muestra de hasta dónde puede llegar la lucha por el poder y el mantenimiento del status quo, a sabiendas de que de la mayor parte de los seres humanos que habitan este planeta, muchos de ellos ciudadanos de nuestra región, no ven garantizado el acceso a prestaciones básicas de salud, agua potable, adecuada nutrición, etc, con desiguales condiciones para hacer frente a todas las vicisitudes que plantea la pandemia, tanto de salud como económicas, políticas, culturales y sociales. No cuentan, en definitiva, con posibilidades reales de hacer efectivo el principio de autonomía en razón de que los condicionantes de todo tipo a los que se encuentran expuestos les quita toda posibilidad de elegir libremente su proyecto de vida y obrar en tal sentido en busca de su felicidad, consecuencia precisamente temeraria del inhumano capitalismo del desastre.

Tal como lo propongo, la Bioética se presenta frente a la amenaza descripta como una forma de pensar y abordarla de manera crítica y con sólidos argumentos humanistas y racionales, alzando la voz en los distintos ámbitos -académicos, políticos, profesionales,

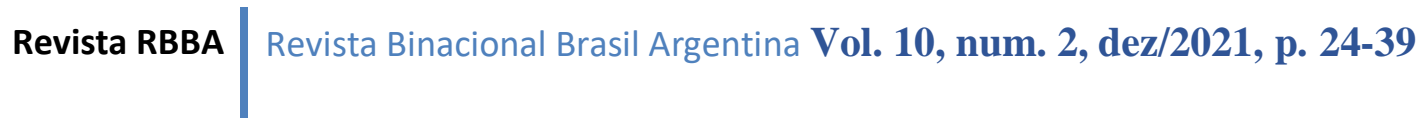


laborales, sociales, etc.- contra toda pretensión de subestimar el rol del Estado como garante de la dignidad de la persona y los derechos humanos, fundamentalmente, del derecho a la salud, y poniendo el foco -por una cuestión de justicia reparadora- en aquellas personas aquejadas por motivos de vulnerabilidad social.

En fin, sin dudas es un arduo trabajo a llevar adelante y ningún esfuerzo será en vano para cuestionar las bases que sustentan la problemática planteada en el presente trabajo. No obstante, -tal como lo hace Gilberto Gil- yo camino con fe, y la fe no suele fallar.

\section{REFERENCIAS}

ASE, Iván. Cobertura Universal en Salud: entre los derechos y el mercado. Ponencia presentada en las Jornadas Nacionales de Derechos Humanos "Decir lo Indecible: Pensar, Aportar e Intervenir desde la perspectiva de Derechos Humanos". Colegio de Psicólogos de Córdoba y FEPRA, Córdoba 25 - 26 de agosto de 2017. Publicada en Salud Mental y Derecho. Derechos Sociales e Intersectorialidad, págs. 235 a 258 , disponible en https://rdu.unc.edu.ar/bitstream/handle/11086/15122/2018\%20Salud_Mental\%20y\%20Derec ho.\%20Derechos $\% 20$ Sociales $\% 20 \mathrm{e} \% 20$ Intersectorialidad.pdf?sequence $=1$

AGRUPACIÓN RAÚL LAGUZZI, Cobertura Universal de Salud vs. Salud Pública. [en línea] Disponible en: https://redbioetica.com.ar/cobertura-universal-de-salud-vs-salud-publica/ [Consulta de 18 de octubre de 2021].

BAUMAN, Z..¿La riqueza de unos pocos nos beneficia a todos?. Editorial Paidós. Colección Estado y Sociedad. Buenos Aires. 2014.

CENTRO DE ESTUDIOS LEGALES Y SOCIALES (CELS), El impuesto a las grandes fortunas. Noviembre 2020. [en línea] Disponible en: https://www.cels.org.ar/web/2020/11/elimpuesto-a-las-grandes-fortunas/ [Consulta del 08 de septiembre de 2021].

CONSELHO NACIONAL DA SAÚDE (CNS). Consolidaçao do SUS e Eleicoes 2020 nesta quarta (21/10). [en línea] Disponible en: http://www.conselho.saude.gov.br/ultimas-noticiascns/1424-cns-debate-consolidacao-do-sus-e-eleicoes-2020-nesta-quarta-21-10 [Consulta: 10 de noviembre de 2020].

DOMÍNGUEZ, M. R. La salud como bien público global en la agenda de desarrollo post2015. Publicado en Revista Jalisco Salud. Año 2. № 3. Septiembre-Diciembre de 2015. P. 120131. Disponible en: https://repositorio.unican.es/xmlui/handle/10902/9909 [Consulta: 19 de octubre de 2021].

GARRAFA, V; CORDÓN, J. Determinantes socias da doença. Publicado en Saúde em Debate, Río de Janeiro. V. 33, N. 83, p/ 388-396, set./dez. 2009; Sacardo et. al, ob. cit.

HEINZMANN, M. y FONTI, D. Bioética Social: Un aporte de la bioética a las controversias socio ambientales. En Revista Cuestiones de Población y Sociedad. Vol. 4, N ${ }^{\circ}$ 4, Año III. 2014. Págs. 63 a 72. Editorial: Centro de Estudios de Población y Desarrollo. [en línea]. Disponible en https://ri.conicet.gov.ar/bitstream/handle/11336/34745/CONICET_Digital

Revista RBBA $\mid$ Revista Binacional Brasil Argentina Vol. 10, num. 2, dez/2021, p. 24-39 
_Nro.e4bef61f-b4f7-44de-b15e-2a6b83ba777c_A.pdf?sequence=2\&isAllowed=y. [Consulta: 16 de octubre de 2021].

KLEIN, N. La doctrina del shock. El auge del capitalismo del desastre. Editorial Paidós. Buenos Aires. 2017.

LA VALLE, R. Sobre medicalización. Orígenes, causas y consecuencias. Parte I. Revista del Hospital Italiano, Buenos Aires, 2014; 34 (2): págs. 67-72.

LUNA, F. De cómo la teoría y la práctica convergen: capas de vulnerabilidades y el COVID19. Coloquio Virtual COVID-19 y bioética, organizado por la UNAM. 24 al 26 de junio de 2020. Disponible en formato video en: http://www.filosoficas.unam.mx/sitio/eventos-pasados.

MAINETTI, José A., El complejo Bioético: pigmalión, narciso y knock. En Revista Latinoamericana de Bioética. Julio-Diciembre 2008. Volumen 8, Número 2, Edición 15. Págs. 30 a 38. Disponible en: http://www.scielo.org.co/pdf/rlb/v8n2/v8n2a04.pdf [Consulta: 15 de octubre de 2021].

MANCHOLA CASTILLO, C., GARRAFA, V., CUNHA, T., HELLMANN, F. El acceso a la salud como derecho humano en políticas internacionales: reflexiones críticas y desafíos contemporáneos. Publicado en: Ciéncia y Saúde Coletiva, 22(7), 2152-2160, 2017. Disponible en: https://repositorio.unb.br/handle/10482/30761 [Captura del 08 de julio de 2020].

MARCUSE, H. Ensayos sobre política y cultura. Editorial Planeta- Agostini. Barcelona. 1986. Ensayo publicado como capítulo 3 del libro colectivo A Great Society? compilado por Bertram M. Gross. Basic Books, New York, 1966.

MÉDICOS SIN FRONTERAS. Sin patentes en pandemia, 2021. [en línea]. Disponible en https://www.msf.org.ar/sin-patentes-en-pandemia [Consulta: 21 de octubre de 2021].

ORGANIZACIÓN MUNDIAL DE LA SALUD (OMS). 2003. [en línea] https://www.who.int/macrohealth/infocentre/advocacy/invertir_en_salud_es.pdf?ua=1[Consul ta: 15 de noviembre de 2020].

ORGANIZACIÓN DE LAS NACIONES UNIDAS. PROGRAMA DE LAS NACIONES UNIDAS PARA EL DESARROLLO (PNUD). Atrapados: alta desigualdad y bajo crecimiento en América Latina y el Caribe. Informe Regional de Desarrollo Humano 2021. 22 de junio de 2021. Disponible en https://dds.cepal.org/redesoc/publicacion?id=5493. [Consulta del $20 \mathrm{de}$ septiembre de 2021].

ORLANDI DEMO, M. L.; ORTH, L. C.; ESMERALDINO MENDES MARCON, C.. Brazil's health-care system. Publicado en The Lancet. V. 394, N. 10213, p. 1992, 30/11/2019. Disponible en: https://www.thelancet.com/journals/lancet/article/PIIS0140-6736(19)326303/fulltext [Consulta: 30 de agosto de 2021]

ORTÍZ MILLÁN, G. Principios de justicia distributiva durante una pandemia. Coloquio Virtual COVID-19 y bioética, organizado por la UNAM. 24 al 26 de junio de 2020. Disponible en formato video en: http://www.filosoficas.unam.mx/sitio/eventos-pasados. [Consulta: junio de 2020].

OXFAM. Una economía para el 99\%, 2017. [en línea]. Disponible en https://www.oxfam.org/es/informes/una-economia-para-el-99 [Consulta: 10 de marzo de 2019].

Revista RBBA $\mid$ Revista Binacional Brasil Argentina Vol. 10, num. 2, dez/2021, p. 24-39 
ROCHA DA CUNHA, T. Bioética Crítica, Saúde Global e a Agenda do Desenvolvimento. Brasília, 2014. Orientador: Cláudio Fortes Garcia Lorenzo Tese (doutorado) - Universidade de Brasília/Programa de Pós-Graduação em Bioética, 2014. 196 p. [en línea]. Disponible en: https://repositorio.unb.br/handle/10482/18133 [Consulta: 15 de noviembre de 2020].

SACARDO, D. P., TITTANEGRO, C. R., RIBEIRO PARIZI CARVALHO, R. DE CARVALHO FORTES, P. A., PEDALINI, L. M., AGUILAR PÉREZ, F. Salud Global y Bioética - disonancias y sinergias en la contemporaneidad. Publicado en Revista Redbioética/UNESCO, Año 3, 1 (5), 64-75, Enero-Julio 2012. [en línea]. https://redbioetica.com.ar/wp-content/uploads/2018/11/Sacardo6475R5.pdf [Consulta: 12 de agosto de 2020].

SCHRAMM, Fermín R.; KOTTOW, Miguel. Principios bioéticos en salud pública: limitaciones y propuestas. Publicado en Cadernos Saúde Pública. V. 5, N. 4, Río de Janeiro, jul/ago 2001. Disponible en: https://www.scielo.br/j/csp/a/DxJCCf8XTBmbQzG6NYNdkhP/abstract/?lang=es [Captura del 20 de julio de 2020].

SVAMPA, M. «Consenso de los Commodities» y lenguajes de valoración en América Latina. Publicado en revista Nueva Sociedad No 244, marzo-abril de 2013, Págs. 30 a 46. [en línea]. Disponible en: http://sedici.unlp.edu.ar/bitstream/handle/10915/96101/Consenso_de_los commodities_y_lenguajes_de_valoraci\%C3\%B3n_en_Am\%C3\%A9rica_Latina.6853_A.pdfDFA.pdf?sequence=1\&isAllowed=y [Consulta: 21 de octubre de 2021].

STOLKINER, A. Ciudadanía global. Disertación en las VI Jornadas Nacionales de Derecho de la Salud, VII Jornadas Rosarinas de Derecho de la Salud. Rosario, 04/09/20. https://www.youtube.com/watch?v=QqOqVahJavE [Consulta: 20 de noviembre de 2020]

TEALDI, J. C. En Diccionario del pensamiento alternativo, dirigido por Biagini, H. E. y Roig, A. A. Editorial Biblos Lexicon. UNLa. Buenos Aires. 2008. Págs. 70 a 72.

TEALDI, J. C. Bioética de los Derechos Humanos. En Diccionario Latinoamericano de Bioética. Diccionario latinoamericano de bioética / dir. Juan Carlos Tealdi. -Bogotá: UNESCO - Red Latinoamericana y del Caribe de Bioética: Universidad Nacional de Colombia, 2008.

UNESCO. “COVID 19 y vacunación en América Latina y el Caribe: Desafíos, necesidades y oportunidades”. 2021. Disponible en: https://unesdoc.unesco.org/ark:/48223/pf0000378377 [Consulta del 18 de septiembre de 2021]

UNICEF. Se inicia vacunación contra el COVID-19 en Haití, 2021. [en línea]. Disponible en: https://www.unicef.org/lac/historias/se-inicia-vacunacion-contra-el-covid-19-en-haiti.

[Consulta: 21 de octubre de 2021].

WILLIAMSON, J. Lo que Washington quiere decir cuando se refiere a reformas de las políticas económica. 1989. Publicado en La Cultura de la estabilidad y el Consenso de Washington. Revista Colección Estudios e Informes $\mathrm{N}^{\circ}$ 15. Edit. Caja de Ahorros y Pensiones de Barcelona, España. 1999. Págs. 67 a 117. [en línea] Disponible en: https://www.caixabankresearch.com/sites/default/files/content/file/2016/09/ee15_esp.pdf. [Consulta: 22 de octubre de 2021].

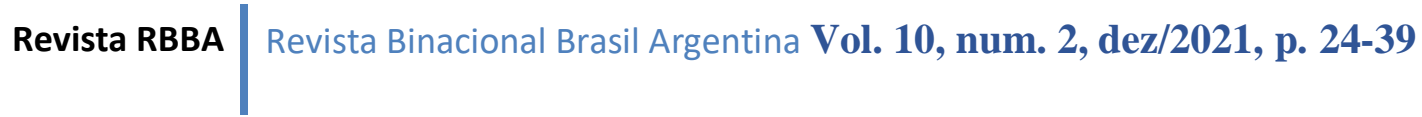




\section{NOTAS}

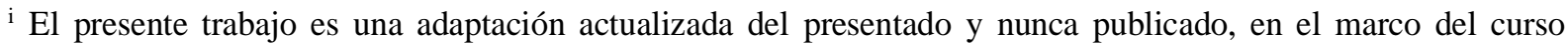
"Fundamentos de la Bioética y Salud Global", ofrecido de modo online en el período entre 10/08/2020 a 18/09/2020 por el Programa de Pósgraduação em Bioética da Pontifícia Universidade Católica do Paraná (PUCPR, Brasil), dirigido por el Dr. Thiago Rocha da Cunha y fue aprobado con la calificación máxima.

${ }^{\mathrm{ii}}$ Luna, F.. De cómo la teoría y la práctica convergen: capas de vulnerabilidades y el COVID-19. Coloquio Virtual COVID-19 y bioética, organizado por la UNAM. 24 al 26 de junio de 2020. Disponible en formato video en: http://www.filosoficas.unam.mx/sitio/eventos-pasados

iii Marcuse, H.. Ensayos sobre política y cultura. Editorial Planeta- Agostini. Barcelona. 1986. Ensayo publicado como capítulo 3 del libro colectivo A Great Society?, compilado por Bertram M. Gross. Basic Books, New York, 1966.

iv La Valle, R.. Sobre medicalización. Orígenes, causas y consecuencias. Parte I. Revista del Hospital Italiano, Buenos Aires, 2014; 34 (2): 67-72

v Tal petición fue sostenida por varios países, como Sudráfrica e India, y unas cuantas organizaciones, entre ellas Médicos Sin Fronteras, para la cual "una suspensión en las patentes de vacunas y medicamentos COVID-19 mientras dure la pandemia podría cambiar la situación actual al anteponer las vidas de las personas a las ganancias". En:.https://www.msf.org.ar/sin-patentes-en-pandemia.

${ }^{v i}$ https://www.unicef.org/lac/historias/se-inicia-vacunacion-contra-el-covid-19-en-haiti.

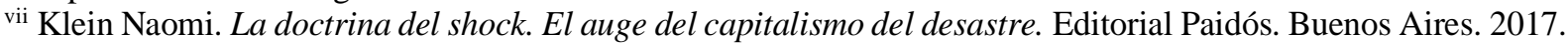

viii Rocha da Cunha, T.. Bioética Crítica, Saúde Global e a Agenda do Desenvolvimento. Brasília, 2014. Orientador: Cláudio Fortes Garcia Lorenzo Tese (doutorado) - Universidade de Brasília/Programa de Pós-Graduação em Bioética, 2014. 196 p.

ix Williamson, J. Lo que Washington quiere decir cuando se refiere a reformas de las políticas económica. 1989. Publicado en La Cultura de la estabilidad y el Consenso de Washington. Revista Colección Estudios e Informes $\mathrm{N}^{\circ}$ 15. Edit. Caja de Ahorros y Pensiones de Barcelona, España. 1999. Págs. 67 a 117.

" Svampa, M. "Consenso de los Commodities» y lenguajes de valoración en América Latina. Publicado en revista Nueva Sociedad No 244, marzo-abril de 2013, Págs. 30 a 46.

${ }^{x i}$ Bauman, Z., ¿La riqueza de unos pocos nos beneficia a todos?. Editorial Paidós. Colección Estado y Sociedad. Buenos Aires. 2014.

xii Heinzmann, M. y Fonti, D. Bioética Social: Un aporte de la bioética a las controversias socio ambientales. Publicado en Revista Cuestiones de Población y Sociedad. Vol. 4, N 4, Año III

xiii OXFAM, Una economía para el 99\%, 2017.

xiv Mainetti, J. A., El complejo Bioético: pigmalión, narciso y knock. Publicado en Revista Latinoamericana de Bioética. Julio-Diciembre 2008. Volumen 8, Número 2, Edición 15. Págs. 30 a 38.

${ }^{\mathrm{xv}}$ Ortíz Millán, G.. Principios de justicia distributiva durante una pandemia. Coloquio Virtual COVID-19 y bioética, organizado por la UNAM. 24 al 26 de junio de 2020.

xvi Stolkiner, A.. Ciudadanía global. Disertación en las VI Jornadas Nacionales de Derecho de la Salud, VII Jornadas Rosarinas de Derecho de la Salud. Rosario, 04/09/20.

xvii Tealdi, J. C. . En Diccionario del pensamiento alternativo, dirigido por Biagini, H. E. y Roig, A. A.. Editorial Biblos Lexicon. UNLa. Buenos Aires. 2008. Págs. 70 a 72.

xviii Organización Mundial de la Salud. 2003.

${ }^{x i x}$ Rocha da Cunha, ob. cit.

xx Sacardo, D. P., Tittanegro, C. R., Ribeiro Parizi Carvalho, R., de Carvalho Fortes, P. A., Pedalini, L. M., Aguilar Pérez, F. Salud Global y Bioética - disonancias y sinergias en la contemporaneidad. Publicado en Revista Redbioética/UNESCO, Año 3, 1 (5), 64-75, Enero-Julio 2012

xxi Manchola Castillo, C., Garrafa, V., Cunha T., Hellmann, F. El acceso a la salud como derecho humano en políticas internacionales: reflexiones críticas y desafíos contemporáneos. Publicado en: Ciéncia y Saúde Coletiva, 22(7), 2152-2160, 2017.

xxii Domínguez, M. R.. La salud como bien público global en la agenda de desarrollo post-2015. Publicado en Revista Jalisco Salud. Año 2. No 3. Septiembre-Diciembre de 2015. P. 120-131

xxiii Se desprende del informe de la UNESCO titulado "COVID 19 y vacunación en América Latina y el Caribe: Desafios, necesidades y oportunidades” que se trata de la región más afectada por la pandemia. 2021.

xxiv Programa de las Naciones Unidas para el Desarrollo, Atrapados: alta desigualdad y bajo crecimiento en América Latina y el Caribe. Informe Regional de Desarrollo Humano 2021. 22 de junio de 2021.

${ }^{\mathrm{xxv}}$ Centro de Estudios Legales y Sociales (CELS), El impuesto a las grandes fortunas. Noviembre 2020.

Revista RBBA $\quad$ Revista Binacional Brasil Argentina Vol. 10, num. 2, dez/2021, p. 24-39 
${ }^{\mathrm{xxvi}}$ Ase, I.. Cobertura Universal en Salud: entre los derechos y el mercado. Ponencia presentada en las Jornadas Nacionales de DDHH "Decir lo Indecible: Pensar, Aportar e Intervenir desde la perspectiva de Derechos Humanos”. Colegio de Psicólogos de Córdoba y FEPRA, Córdoba 25 - 26 de Agosto de 2017.

xxvii Manchola Castillo et. al, ob. cit.

xxviii Agrupación Raúl Laguzzi, Cobertura Universal de Salud vs. Salud Pública.

${ }^{x x i x}$ Conselho Nacional da Saúde (CNS). Consolidaçao do SUS e Eleicoes 2020 nesta quarta (21/10)..

${ }^{x x x}$ Orlandi Demo, M. L.; Orth, L. C.; Esmeraldino Mendes Marcon, C.. Brazil's health-care system.

xxxi Agrupación Raúl Laguzzi, ob. cit.

xxxii Marcuse, ob. cit.

xxxiii http://portal.unesco.org/es/ev.php-URL_ID=31058\&URL_DO=DO_TOPIC\&URL_SECTION=201.html

xxxiv Tealdi, J. C.. Bioética de los Derechos Humanos. En Diccionario Latinoamericano de Bioética. Diccionario latinoamericano de bioética / dir. Juan Carlos Tealdi. -Bogotá: UNESCO - Red Latinoamericana y del Caribe de Bioética: Universidad Nacional de Colombia, 2008.

xxxv Rocha da Cunha, ob. cit.

xxxvi Diccionario Latinoamericano de Bioética. Dir. Juan Carlos Tealdi. Bogotá: UNESCO - Red Latinoamericana y del Caribe de Bioética: Universidad Nacional de Colombia, 2008 xxviii, 660 p. ISBN: 978-958-701-974-2

xxxvii Ejemplares disponibles on line en: https://redbioetica.com.ar/category/revista-redbioectica-unesco/ xxxviii Garrafa, V.; Cordón, J.. Determinantes socias da doença. Publicado en Saúde em Debate, Río de Janeiro. V. 33, N. 83, p/ 388-396, set./dez. 2009; Sacardo et. al, ob. cit.

xxxix Schramm, F. R.; Kottow, M. Principios bioéticos en salud pública: limitaciones y propuestas. Publicado en Cadernos Saúde Pública. V. 5, N. 4, Río de Janeiro, jul/ago 2001.

${ }^{x l}$ Rocha da Cunha, ob. cit. 